\title{
Long stay patients in a psychiatric hospital in Lagos, Nigeria
}

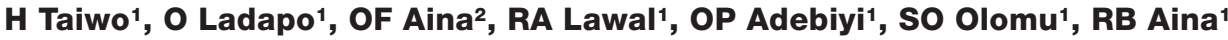 \\ 1Psychiatric Hospital, Yaba, Lagos, Nigeria \\ ${ }^{2}$ College of Medicine, University of Lagos, Lagos, Nigeria
}

\begin{abstract}
Objective: In the face of recently introduced government health reform and the dwindling number of available beds for acutely ill patients, a cross sectional study was carried out on long-stay patients at the 100 years old psychiatric hospital Yaba, Lagos, Nigeria with a view to discharging most of them. Method: Necessary consent was obtained from the Hospital Research and Ethical Committee. All the long-stay patients were evaluated with a specially designed proforma to elicit socio-demographic, clinical and long-stay variables. Further more, each of them had clinical assessment to make diagnosis in accordance with ICD 10 and finally, the subjects were also assessed with the Brief Psychiatric Rating Scale (BPRS). Results: Fifty-one (51) subjects; that is, occupying $10.7 \%$ of the hospital functional beds fulfilled the criteria of long-stay. They included 36 (70.6\%) males and 15(24.4\%) females. The mean age was $47.3 \pm 16.5$ years with age range of $18-92$ years. The average length of stay was $11.4 \pm 15.0$ years and range of 0.5 to 57 years; with significant gender difference (males higher than females) $(t=3.51, p<0.02)$. The vast majority of the subjects were diagnosed with schizophrenia (84.3\%), followed by mental retardation with seizure disorder (5.9\%). One-third (33.3\%) of the subjects had co-morbid physical pathologies most especially epilepsies, hypertension, Koch's disease, HIV/AIDS. Despite being on high doses of antipsychotics (conventional and/or atypical) the majority of the subjects (86.3\%) exhibited poor mental state with BPRS scores of $\geq 10$. The mean BPRS score was $23.6 \pm 22.0$ and range of $4-56$ with a significant gender difference $(t=3.66, p<0.02)$. Conclusion: These patients would continue to require long-stay hospitalization despite been a burden to the study center; or, in the alternative provision of mid-way facilities for their rehabilitation.
\end{abstract}

Key Words: Long-stay; Psychiatric hospital; Patients; West-Africa; Discharge

Received: 18-04-2007

Accepted: 07-07-2007

\section{Introduction}

In psychiatric practice, some mentally ill patients spend their life in continuous or prolonged hospitalization; that is, as long stay patient., ${ }^{1,2}$ This is due among other reasons to severe mental illness with poor symptom control, substance dependence, homelessness and abandonment by the patients' relatives. ${ }^{3,4}$ Furthermore, in developing countries such as Nigeria, the situation is slightly different. The issue of long-stay patients is intertwined with the historical development of orthodox psychiatric care. In the early 20th century, asylums were established in selected towns and cities in the country by

\section{Correspondence:}

Dr OF Aina

Department of Psychiatry, College of Medicine, University of Lagos,

PMB 12003, Lagos, Nigeria

email: ainafran@yahoo.com the then colonial powers. These were to serve as places of confinement or long-stay for psychiatrically ill offenders. ${ }^{5,6}$ Over the years, these asylums were converted to fully-fledged psychiatric hospitals; with most of the long-stay offender inmates remaining in these facilities till date. ${ }^{6}$ Another major source of long-stay patients is from the population of vagrant, psychotic individuals in the country. From time to time, the Nigerian print media focuses on this situation. ${ }^{7,8}$ Some of these vagrant patients have over the years found their way to hospital, with a prolonged stay, by being brought to the centre by government health officials or most times by concerned members of the public. ${ }^{9}$ Finally, in the study centre, the additional source of long-stay patients include some abandoned mentally ill returnee Nigerian soldiers from both the Second World War as well as the Nigerian civil war of 1967-1970. However, the cost of prolonged hospitalization care for these patients is borne by the hospital management. 
Over the years, long-stay patients have been extensively studied in Europe and North America. 10,11,12 However, in such developed nations and since the 1950s, deinstitutionalization led to a remarkable decline in the number of long-stay patients and closure of a number of the then mental health asylums $s^{13,14}$, with the alternative provision of community care. ${ }^{12,15}$ However, in such countries, studies within the past few years have shown a new era of mental health care i.e. reinstitutionalization. ${ }^{2}$ Various factors are responsible for this. Some outcome studies of discharged patients reported worse clinical profiles for them following discharge. ${ }^{16}$ Further, many of the patients have severe mental illness that are difficult to manage in the community facilities, hence the necessity for prolonged long-stay hospitalization. ${ }^{14,17}$

The rationale for this study is the need by the hospital (study centre) management to discharge these patients in the face of ongoing government health reform, as well as increasing numbers of new patients that would require hospitalization but most times could not be admitted due to inadequate bed space.

\section{Method \\ Study Setting}

The study took place at a psychiatric hospital, Yaba, Lagos Nigeria. The hospital was established 100 years ago (1907); then known as Yaba Lunatic asylum. ${ }^{5}$ It has undergone subsequent expansion and modernization to attain its present fully fledged psychiatric hospital status with a 535 bed capacity; however, 59 of these beds have remained unused over the years due to these beds being non-serviceable and thus out of use; hence leaving a functional bed compliment of 476. The main hospital centre is at Yaba with an annex at Oshodi, also in Lagos, and about a distance of $6 \mathrm{~km}$ from the main centre. In addition to patients' care, there are various training programmes such as postgraduate psychiatric residency and occupational therapy in place. ${ }^{18}$

\section{Subjects and Procedures}

It was a cross-sectional survey of all the long-stay patients in the study centre (including the Oshodi annex). Necessary approval to carry out the study was sought and obtained from the Research and Ethnical committee of the hospital.

Permission was also given to review the case notes of the longstay subjects. In this study, "long-stay" was defined as a patient that has been on continuous hospital admission for at least 6 months.

Two research assistants were recruited from the social welfare department of the hospital to administer a specially designed proforma on the subjects. The pro forma was designed to elicit the following information from each of the subjects: Socio demographic data, date and mode of admission, social and rehabilitation plan and necessary clinical details from the case-note of the subjects. A visiting researcher from a neighbouring University department of psychiatry was a member of the study group. The data obtained on each subject by the research assistants was made blind to him. Each of the subjects was subsequently evaluated clinically by a consultant psychiatrist. The clinical diagnosis on each subject was in accordance with ICD-10 criteria. ${ }^{19}$ Furthermore, each of the subjects was assessed with the modified 18-item standard version of the Brief
Psychiatric Rating Scale (BPRS). ${ }^{20}$ Each of the items is rated $0-6$, and the instrument is one of the most frequently used rating scales in psychiatry to assess severity of symptoms in patients. ${ }^{21}$

\section{Data Analyses}

The data obtained: socio-demographic profiles and clinical details including the BPRS scores were entered into a SPSS (version-10) spreadsheet. Frequency tables, means and chi square statistics were obtained. Furthermore, differences between genders on baseline characteristics such as mode of admission, length of stay and clinical data such as dose of necessary medications, BPRS scores were summarized as percentages with 95 percent confidence intervals (CIs) and also compared using a 't' test.

\section{Results \\ Socio-demographic characteristics:}

Overall, fifty one (51) patients utilizing just over one tenth (10.7\%) of the hospital functional bed spaces fulfilled the criteria of "long-stay". They were made up of 36 (70.6\%) males and 15 (29.4\%) females. In terms of religion, 38 (74.5\%) were Christians and the remainder, 13 (25.5\%), were Muslims. The mean age of the subjects was $47.3(+16.5)$ years with an age range of 18 to 92 years; the mean age of females (51.6 years) was higher than that of the males (45.4 years). In term of marital status, the majority were never married, i.e single: 45(88.2\%); with only 3(5.9\%) having been married, 2(3.9\%) were widowed and l(2.0\%) was separated. The majority: $41(80.4 \%)$ were unemployed, 4(7.8\%) had a paid job outside the hospital, 3(5.9\%) had a "rehabilitation job" within the hospital and 3(5.9\%) were retirees.

\section{Length of Stay and Mode of Admission}

The average length of stay of the subjects was 11.4( \pm 15.0 ) years with a range of 0.5-57 years. The highest percentage (45.1\%) of subjects was in the group of very long-stay (>5 years) followed by the long-stay group of 6 months to one year (29.4\%) and lastly $25.5 \%$ for the moderately long-stay ( 1 year to 5 years) category of patients (Table I). In terms of gender distribution in the length of stay, the mean stay was higher for the males ( 11.8 years) than the females ( 9.7 years); and the difference was significant $(t=3.51, \mathrm{P}<0.02$ at $95 \%$ Confidence Interval): Table I. The majority, 35 (68.6\%) of the subjects were brought in for admission by their relatives, but 5 of them were abandoned in the hospital by their relatives. This was followed by vagrant psychotics picked from the street and brought into the hospital by either the "Good Samaritans" or government officials, 10(19.6\%). Six (11.8\%) were committed to indefinite hospital confinement by the law courts for different offences most especially murder cases (Table I).

\section{Clinical Profiles}

Over three-quarters, 44(86.3\%), of the subjects were diagnosed (according to ICD-10 criteria $^{19}$ ) to have schizophrenia. This was followed by with mental retardation and seizures, 3(5.9\%). The remainder, 4(7.8\%), had the diagnoses of mental retardation and/ or undifferentiated psychosis. Seventeen (33.3\%) of the subjects had one or more types of co-existing physical pathologies which included epilepsies: 5(9.8\%); hypertension, 3(5.9\%); 2(3.9\%) had 
Table l: Length of stay and mode of admission/ gender distribution

\begin{tabular}{|c|c|c|c|c|c|c|c|}
\hline \multirow[t]{3}{*}{ Length of stay } & \multicolumn{6}{|c|}{ Mode of Admission } & \multirow[t]{3}{*}{ Total (\%) } \\
\hline & \multicolumn{2}{|c|}{ Brought by relatives } & \multicolumn{2}{|c|}{ Vagrants } & \multicolumn{2}{|c|}{ Court Confinement } & \\
\hline & $M$ & $F$ & $M$ & $F$ & $M$ & $F$ & \\
\hline $\begin{array}{l}6 \text { months - 1year } \\
\text { (Long-stay) }\end{array}$ & 12 & 3 & - & - & - & - & $15(29.4)$ \\
\hline $\begin{array}{l}\text { 1year - 5years } \\
\text { (Moderately Long-stay) }\end{array}$ & 7 & 2 & 2 & 2 & - & - & $13(25.5)$ \\
\hline $\begin{array}{l}>5 \text { years } \\
\text { (Very Long-stay) }\end{array}$ & 7 & 4 & 3 & 3 & 6 & - & $23(45.1)$ \\
\hline Total & 26 & 9 & 5 & 5 & 6 & - & $51(100.0)$ \\
\hline
\end{tabular}

HIV/AIDS; pulmonary tuberculosis $1(2.0 \%)$ and the remainder, 6(11.8\%), had either asthma or various dermatological disorders.

The clinical severity of the subjects' psychopathologies, as estimated by the modified BPRS scores, showed quite a number of them ( $n=44 ; 86.3 \%)$ still exhibited prominent psychotic symptoms with BPRS Scores of $>10$. The gender difference on BPRS scores was significant, males greater than females ( $t=3.66, P<0.002)$. Overall, the mean BPRS score of the subjects was $23.6+22.0$ with a range of $4-56$. The 44 subjects with schizophrenia had a slightly lower mean BPRS score of 23.5 compared to the remaining 7 subjects whose mean BPRS score was 24.3 (see Table II for BPRS score distribution).

Regarding drug treatment (i.e. medication), as at the time of conducting the study, 21 (41.2\%) of the subjects were on conventional antipsychotics alone, followed by 15(29.4\%) on a combination of conventional and second generation antipsychotics (SGAs). Ten (19.6\%) were on a combination of conventional antipsychotics and antiepileptic drugs (AEDs); four (7.8\%) subjects were on a combination of antipsychotics and other drugs such as antihypertensive, antiretroviral and anti-TB drugs. Finally one (2.0\%) was on AEDs only. For the subjects on conventional antipsychotics,

\begin{tabular}{|l|l|l|ll|}
\hline \multicolumn{6}{|c|}{ Table II: BPRS Scores and gender distribution } \\
\hline BPRS Scores & Male & Female & Total & (\%tage) \\
\hline $4-9$ & 6 & 1 & 7 & $(13.7)$ \\
$10-19$ & 10 & 6 & 16 & $(31.4)$ \\
$20-29$ & 7 & 3 & 10 & $(19.6)$ \\
$30-39$ & 8 & 4 & 12 & $(23.5)$ \\
$40-49$ & 4 & 1 & 5 & $(9.8)$ \\
$>50$ & 1 & - & 1 & $(2.0)$ \\
\hline Total & 36 & 15 & 51 & $(100.0)$ \\
\hline
\end{tabular}

' $t$ ' $=3.66$ at $95 \%$ confidence interval and sig. ( 2 - tailed): 0.02 .

$X^{2}=6.00$ with $\mathrm{df}=5$. the majority ( $\mathrm{n}=24 ; 47.1 \%$ ) were on chlorpromazine equivalent doses of 500-1000mg per day, followed by $13(25.5 \%)$ on $<500 \mathrm{mg}$ per day and finally $11(21.6 \%)$ were on $>1000 \mathrm{mg}$ per day.

\section{Correlation analysis}

Using non-parametric correlation analysis, significant correlations were established between age of the subjects and such factors as religion, marital status and length of stay, $r=.43 * *, .41^{* *}$ and $.52^{* *}$ respectively. There was a significant negative relationship between gender and diagnosis $(r=-$ .28*). A positive significant relationship also existed between length of stay and BPRS scores $\left(r=.36^{*}\right)$; but a negative correlation with mode of administration $\left(r=-.33^{*}\right)$ and dose of antipsychotic medication $\left(r=-0.31^{*}\right)$. Significant correlations also existed between co-morbid organic pathology and dose of antipsychotic $(r=.34 *)$; between medication and BPRS Scores $\left(r=.30^{*}\right)$. Factors such as religion, diagnosis, employment and dose of antipsychotics had no significant relationship with other variables.

\section{Discussion}

In the current study, the long stay subjects occupied over one tenth (10.7\%) of the functional hospital beds. This was less than figures obtained from previous studies i.e. $12 \%$ in a British study by Cowan and Walker (2005) 22 and 1 1\% from a local study in Calabar, Nigeria. ${ }^{6}$ However, this $10.7 \%$ bed occupancy by the long stay patients in our study remains quite high placing a heavy burden and pressure on the hospital facilities, especially with the current increasing number of acutely ill patients being brought to the centre on a daily basis that require hospitalization. From time to time, some of these new and acutely ill patients fail to secure beds on the wards and thus have to be discharged from the emergency unit after initial 'first aid' treatment.

The male preponderance (70.6\%) of long stay patients in our study is similar to findings from the western world. ${ }^{17,22}$ The possible explanation in our study could be that male psychotic patients are more difficult to manage in the community hence increasing the likelihood of abandonment 
in hospital, especially for chronic cases. Again more males were long-stay patients from court confinement due to criminal offences most especially homicide. The mean age of our patients $(47.3+16.5$ years) is similar to findings from previous studies: 45.2 years by Trieman and Leff (2002)17, 54 years (Leff and Trieman, 2000) ${ }^{14}$ and 43.1 years in the Calabar, Nigerian study. ${ }^{6}$

The mean length of stay in the study was $11.4+15.0$ years (range of 0.5- 57 years). This is similar to findings from the Calabar study (1 $1.6+9.0$ years). ${ }^{6}$ However, compared to figures from western studies, the mean length of stay varies very widely between different western centres depending on the extent of de-institutionalization programme in place. 1,10,11 The definition of length of stay varies. While some studies adopted minimum of one year of continuous hospitalization, others adopted 6 months (as in the current study) as definition of long stay. ${ }^{23}$ In their study, Okin et al (1990) ${ }^{23}$ grouped the lengths of stay into 3 categories: 6 months up to 1 year as long stay; moderately long (1-5years) and very long ( $>5$ years). Thus, in the current study, 15 (29.4\%) of the subjects were long-stay, 13 (25.5\%) moderately long-stay and 23(45.1\%) very long-stay. Furthermore, in the current study offender subjects on court confinement to the hospital and vagrant psychotics picked up from the streets were more likely to be in the category of very long-stay patients. Consequently, a significant correlation, albeit negative one $\left(r=-.33^{*}\right)$ existed between length of stay and mode of admission to the hospital.

\section{Table III: Correlation matrix}

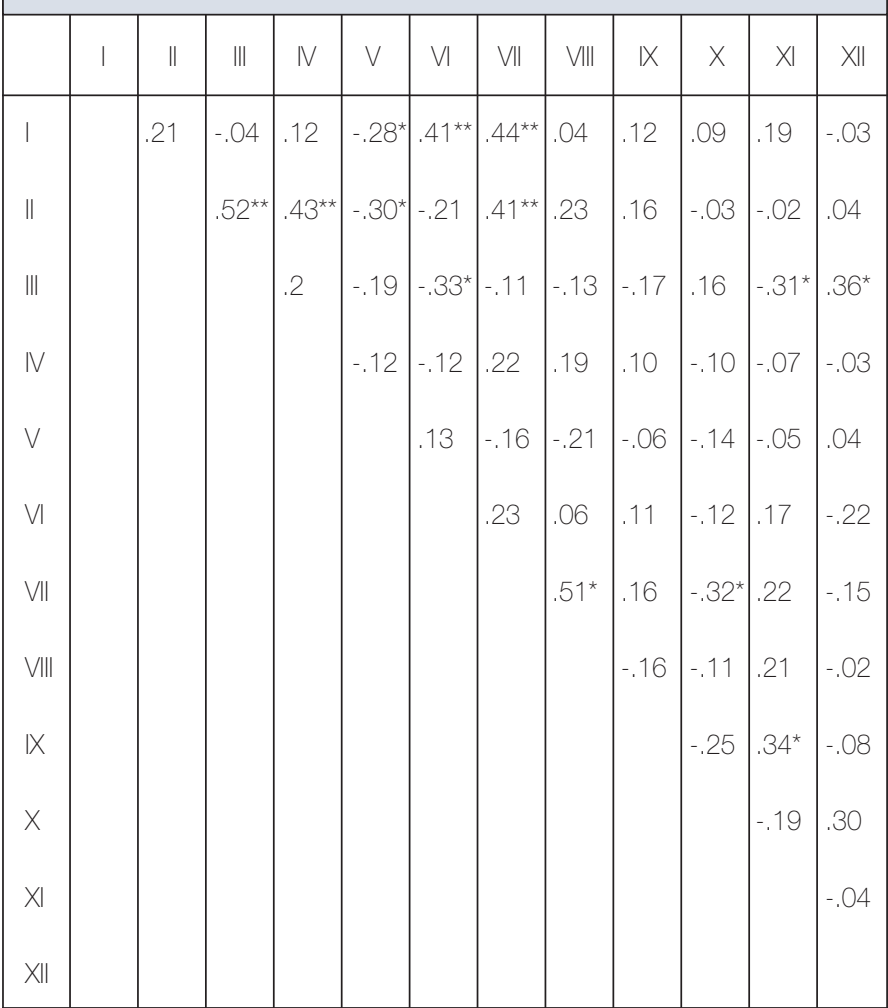

KEYS: I: SEX, II: AGE, III: LENGTH OF STAY, IV: RELIGION, V: DIAGNOSIS, VI: MODE OF ADMISSION, VII: MARITAL STATUS, VIII: EMPLOYMENT, IX: CO-MORBID ORGANIC PATHOLOGY X: MEDICATION (DRUG TREATMENT), XI: DOSE OF ANTIPSYCHOTIC, XII: BPRS SCORES
As might be expected, over four-fifths (86.3\%) of the subjects had diagnosis of schizophrenia which is similar to findings from previous studies. 1,11,14,17,24 Schizophrenia is known to be associated with poor clinical and social outcome including a high rate of unemployment and being unmarried or having poor marital adjustment. ${ }^{25,26}$ Even in developing countries such as Nigeria where an initial WHO study (1979 ${ }^{27}$ found a better prognosis for schizophrenia, subsequent studies have shown worse clinical, occupational and social outcome among schizophrenic patients. ${ }^{28}$ In the current study, apart from the factor of long-hospital confinement, the prevalence of schizophrenia among the subjects could partly explain the poor social outcome of high rate of being unmarried i.e. single (88.2\%) and unemployment (80.4\%). Thus in our study, there exists a negative correlation (although not significant) between the variable, diagnosis and the factors of marital status ( $r=-.16)$ and employment ( $r=-.21)$ : Table III.

In the current study, it is clinically significant that $17(33.3 \%)$ i.e. one-third of our subjects had one or more types of co-morbid organic pathology such as hypertension, HIV/AIDS, Koch's disease, epilepsy etc. This accords with findings from some previous studies that showed long-stay patients are at risk of developing physical health problems ${ }^{29,30}$; hence the advocated need to put in place a necessary physical health monitoring programme for such patients. In line with this, a general healthcare clinic (Harvey Road Community Clinic) was established in our centre about five years ago to take care of the physical health needs of inpatients, members of staff and interested members of the public from the neighbourhood. Furthermore, there are two consultant physicians (a Neurologist and a Cardiologist) on part-time locum appointment within the hospital (the study centre) to take care of specialized or complicated organic pathologies. Again, a referral agreement is in place between our centre and the surrounding general/ teaching hospitals to care for ill-patients (from our centre) that would require admission in such facilities.

As expected, nearly all the subjects (50 out of 51) were on antipsychotic medication, either the conventional type alone, or in combination with SGAs or AEDs. Our results also showed most of the subjects were on adequately high daily doses of the antipsychotic drugs. However, despite the medication and the rehabilitation programme put in place by the social welfare unit of the hospital, the mental state of most of the subjects was poor, with active psychotic symptoms as evidenced by greater than four-fifths (86.3\%) of patients having high BPRS scores of $\geq 10$. Again the mean BPRS score in the study was on the high side of $23.6+22.0$. Thus, it is obvious that due to the severity of their mental illness and poor treatment response, it would be difficult to discharge these patients without alternative provisions despite the burden on the hospital.

\section{Conclusion}

In conclusion, to ease the burden of long-stay patients, it is advocated for local trial in Nigeria of the so called "institutionalization without walls"2 and/ or the establishment of special "rehabilitation villages" as is practiced in some East African countries4 to cater for this category of long-stay patients. 


\section{References}

1. Lelliot P; Wing J \& Clifford P. A national audit of new long-stay psychiatric patients I: Method and description of the cohort. British Journal of Psychiatry 1994; 165: $160-169$.

2. Priebe S. Institutionalization revisited with and without walls (Editorial). Acta Psychiatr Scand 2004; 1 10:80-81.

3. Rogers ES; Anthony W; Lyass A. The nature and dimensions of social support among individuals with severe mental illnesses. Commun Ment Health J. 2004; 40:437 - 450.

4. Rösler W. Psychiatric rehabilitation today: An overview World Psychiatry. October 2006: 151 - 157.

5. Boroffka A. Psychiatric Care in Nigeria. Psychopathologie Africaine 1995 - 1996; XXVII; I: 27 - 36.

6. Ekpo M; Oyiyega M; Ayeni F. Profile of long stay patients in Federal Psychiatric hospital, Calabar. In Association of psychiatrists in Nigeria (ed.). Book of procedure, Annual Conference of Association of psychiatrists in Nigeria, November 2000 at federal psychiatric hospital. Calabar, Nigeria: pp116-121.

7. Anaele A. Bad Omen: Up, up goes population of crazy Nigerians; and few psychiatrists to treat them. In S. Nwosu (ed) Sunday Sun. The Sun Publishing Limited, Apapa, Lagos, Nigeria July 23, 2006; pp47.

8. Oshisada V. The upsurge of mental patients. In Debo Adesina (ed) Guardian. Guardian Newspapers Ltd, Isolo, Lagos, Nigeria. August 28 2006: pp34.

9. Umoh GE. Reaching the unreachable. In O.B. Orija (ed) 90th Anniversary (1907 - 1997) commemorative brochure, psychiatric hospital Yaba 1997: pp57.

10. Platman SR; Karahasan A; Booker TC. The new long-term patients in the public mental hospital. Am J Psychiatry 1983; 140:606-608.

11. Kastrup M. Prediction and profile of the long-stay population. Acta Psychiatr Scand 1987; 76:71-79.

12. Fuhrmann $R$ and Reeder C. Personal finances for long-stay psychiatric patients resettled into the community. Psychiatric Bulletin 1996; 20; 4:215-217.

13. McGrew JH; Wright ER; Pescosolido BA. Closing of a state hospital: an overview and framework for a case study. Journal of Behavioural Health Sciences and Research 1999; 26: 236-245.

14. Leff J and Trieman N. Long-stay patients discharged from psychiatric hospitals. Social and clinical outcomes after five years in the community. The TAPS Project 46. British Journal of Psychiatry 2000; 176: $217-223$.

15. Madianos MG. Recent advances in community psychiatry and psychosocial rehabilitation in Greece and the other southern European countries. International Journal of Social Psychiatry 1994;
$40: 157-164$

16. Popkin MK; Lurie N; Manning W et al. Changes in the process of care for Medic aid patients with schizophrenia in Utah's prepaid mental health plan. Psychiatric Services 1998; 49; 518 - 523.

17. Trieman $N$ and Leff J. Long-term outcome of long stay psychiatric inpatients considered unsuitable to live in the community. The taps project 44. British Journal of psychiatry 2002; 181; $428-432$.

18. Malomo I.O.; Aina OF; Ladapo HTO and Owoeye AO. Ten year mortality review in a pioneer psychiatric hospital in West Africa. East African Medical Journal 2003; 80:379 - 383.

19. World Health Organisation. The ICD-10 Classification of Mental and Behavioural Disorders. Clinical descriptions and diagnostic guidelines. Oxford University Press, 1992.

20. Overall JE \& Gorham DR. The Brief Psychiatric Rating Scale. Psychological Reports 1962; 10: 799-812.

21. http://wwwl.elsevier.com/homepage/sab/ratingscales/datal chapters/ch3sample. htm. The Brief Psychiatric Rating Scale, the extension BPRS, the children's BPRS, the Psychiatric Disintegration Scale and the Psychiatric Symptom (assessment) Scale (BPRS, BPRSE, BPRSC, PDS, SSS, PSAS). 16-2-2003.

22. Cowan C\&Walker P. New long-stay patients in a psychiatric admission ward setting. Psychiatric Bulletin 2005; 29: 452-454.

23. Okin RL; Pearsall $D$ and Athearn T. Predictions about new long-stay patients: Were they valid? American Journal of psychiatry 1990; 147; 12: 1596-1601.

24. Thornicroft G; Bebbington P; Leff J. Outcomes for long-term patients one year after discharge from a psychiatric hospital. Psychiatric Services 2005; 56; 11; 1416-1422.

25. Cantor GE; Selten JP. Schizophrenia and migration: A meta-analysis and review. Am J. Psychiatry 2005; 162: 12 - 24.

26. Tulloch AD; Fearon P; David AS. Social outcomes in schizophrenic: from description to action. Curr Opin Psychiatry 2006; 19:140-144.

27. World Health Organsation. Schizophrenia: An International Follow-up study. Geneva: WHO, 1979.

28. Makanjuola ROA and Adedapo SA. The DSM-III concepts of schizophrenic disorder and schizophrenifrom disorder. A clinical and prognostic evaluation. British Journal of Psychiatry 1987; 151: 611-618.

29. Cormac I; Ferriter $M \&$ Martin D. Improving the physical health of long-stay psychiatric in-patients. Advances in Psychiatric Treatment 2004; 10: 107-115.

30. Cormac I; Ferriter M; Benning R and Saul C. Physical health and health risk factors in a population of long-stay psychiatric patients. Psychiatric Bulletin 2005; 29: 18-20. 